\title{
Utilising Content Marketing Metrics and Social Networks for Academic Visibility
}

\begin{abstract}
There are numerous assumptions on research evaluation in terms of quality and relevance of academic contributions. Researchers are becoming increasingly acquainted with bibliometric indicators, including; citation analysis, impact factor, h-index, webometrics and academic social networking sites. In this light, this chapter presents a review of these concepts as it considers relevant theoretical underpinnings that are related to the content marketing of scholars. Therefore, this contribution critically evaluates previous papers that revolve on the subject of academic reputation as it deliberates on the individual researchers' personal branding. It also explains how metrics are currently being used to rank the academic standing of journals as well as higher educational institutions. In a nutshell, this chapter implies that the scholarly impact depends on a number of factors including accessibility of publications, peer review of academic work as well as social networking among scholars.
\end{abstract}

Keywords: Bibliometrics, Webometrics, Social Media, Web 2.0, Citation Analysis, Impact Factor, Academic Clout, Google Scholar, ResearchGate, Academia.edu, Altmetrics. 


\section{INTRODUCTION}

Academic contributions start from concepts and ideas. When their content is of a high quality and is relevant to other scholars, they could be published in renowned, peer-reviewed journals. Many researchers are resorting to online full text databases, institutional repositories or online open access journals in order to disseminate their findings. The internet has brought an increased engagement among peers, over email or video communications. In addition, the web and online academic networks have surely helped to enhance the fruitful and collaborative relationships among researchers. Notwithstanding, researchers are increasingly sharing their knowledge with colleagues as they present their papers in seminars and conferences. After publication, their contributions may then be cited by other scholars, including students.

The researchers' visibility does not solely rely on the number of publications they produce. Both academic researchers as well as their institutions are continuously being under scrutiny as they are rated and classified by independent reviewers. Very often citations appear in publications in highly reputable journals or well-linked homepages that promote scholarly content (Thelwall, 2008, 2009; Bonzi \& Snyder, 1991). Publications are usually ranked through bibliometrics that assess the individual researchers as well as their organisational performance (Thelwall, 2008; Delgado López-Cózar, Robinson-García \& Torres-Salinas, 2014). Such metrics measure the effectiveness of academic publications. Citation analysis, impact factor (IF), h-index, webometric analysis, altimetrics and social academic networks are some of the most commonly used measures that assess the quality and relevance of scholarly work. High bibliometric scores and numerous citations are widely believed to constitute the academic reward system. The most cited authors are usually endorsed by peers for their significant contribution to knowledge. As a matter of fact, citations are at the core of scientometric methods. They have been (and are being) used to measure the academic visibility and impact of scholarly work (Kousha \& Thelwall, 2007; Moed, 2005, 2006; Borgman, 2000).

This chapter's objective is to critically review and analyse extant literature on the subject of academic branding. It clearly explains how the content marketing of individual researchers' and of their educational institutions' publications may lead to improvements in their academic standing and increased reputation. The author re-examines the communication structures and processes of scholarly communication (Thelwall \& Kousha, 2015a, 2015b, 2015c; Kousha \& Thelwall, 2007; 
Borgman \& Furner 2002) among academic institutions. At the same time, this contribution presents relevant literature on the most popular scholarly metrics. It also reports how the evolution of WEB2.0 and the ubiquity of online academic networks have helped individual researchers to engage with their peers. In conclusion, this chapter implies that there is potential for scholars to use content marketing metrics for their academic standing (Thelwall \& Kousha, 2015a, 2015b; Orduna-Malea \& Ontalba-Ruipérez, 2013; Adler \& Harzing, 2009; Thelwall \& Harries, 2004; Wilson, 1999; Tague-Sutcliffe, 1992).

\section{BACKGROUND}

The independent evaluation of any scholarly work is a notoriously difficult and arduous task. Ideally, academic contributions ought to be scrutinised by qualified experts in their field. These scholars are recognised and accredited for both quality and quantity according to previously established rules. Essentially, such evaluation is called peer-review and is usually carried out by research committees. Yet, very often certain journal reviewers could lack specialist knowledge to assess research, particularly empirical data. Hence, committees use secondary criteria including crude publication counts, number of downloaded documents, journal prestige, the reputation of individual authors and their institutions; as well as other metrics in order to estimate the importance and relevance of particular research fields. Hence, it is the scope of this chapter to shed light on academic marketing which relies on the use and application of different metrics to build the reputation and standing of scholars, institutions and research centres. Authoritative, multidisciplinary content covers over 10,000 of the highest impact journals worldwide, including open access journals and over 110,000 conference proceedings (Courtault, Hayek, Rimbaux \& Zhu, 2010; Thomson Reuters ISI Web of Science, 2010). References are sorted in such a way in order to reveal how often any given publication has been cited within a given time period, and by whom. Afterwards, these results are published through the Thomson Reuters Science Citation Index (SCI). Hence, SCI gives a breakdown of the annual citation rate of papers, by author or by research group. SciVerse Scopus is another commercial database which was launched in November 2004. Its providers claim that their system provides the largest abstract and citation database containing peer-reviewed research literature: scientific journals, books and conference proceedings (SciVerse Scopus, 2015). The journal impact factors which are published by SCI or in Scopus are widely regarded as quality rankings for journals. Such metrics are used extensively by leading journals in their content marketing endeavours. Other excellent databases include the Social Science Research Network (SSRN) database, which contains a very large number of working papers and publications in the realms of social sciences (including economics, finance, 
accounting, and business); research papers in economics database for economics; the Scopus subscription-based database, and free Internet databases, such as Google Scholar (Orduna-Malea, Ayllón, Martín-Martín \& López-Cózar, 2015; Labbe 2010), Researchgate (Kousha \& Thelwall, 2014), Academia.edu, Mendeley and the like (Haustein, Peters, Bar-Ilan, Priem, Shema \& Terliesner, 2014). Each of these databases have their own strengths and weaknesses.

\section{Citation Analysis of Academic Papers}

The majority of academic papers, notes, reviews, corrections and correspondence published in scientific journals contain citations to other academic contributions (Eysenbach, 2011; Kousha \& Thelwall, 2007; Brooks, 1986; Garfield, 1979). These citations comprise the author(s)' name(s), date, title, journal name, volume (issue), pages and url (or doi). Thousands if not millions of studies have used such data from citation indices (Thelwall, 2008; Bonzi \& Snyder, 1991). These bibliographic applications extract, aggregate and analyse quantitative aspects of bibliographic information. Therefore, citations constitute formal and explicit links between papers that usually share common features (Shuai, Pepe \& Bollen, 2012; Brooks, 1986). A citation index is built around these links as the latest academic contributions cite and identify previous publications. Thanks to citations a literature search can find from one to dozens of additional papers on a subject just by knowing one that has been cited. Every paper provides a list of new citations from which to continue the search (Athar, 2014; Garfield, 1979). Relevant data for citation analysis is derived from in-text references and bibliographies of publications. Indicators of scholarly 'impact', 'influence' or 'quality' are applied both in the study of academic communication and when assessing the researchers' performance (Moed, 2005). Hence, citations represent the documents' content (Athar, 2014; Brooks, 1986). They are an extensive dimension of retrieving publications that have been cited in previous works (Knothe, 2006).

The citation analysis offers enormous possibilities for the tracing of trends and developments across different research areas (Bonzi \& Snyder, 1991). This metric has become the de-facto standard in research evaluation. In fact, publications can be simply evaluated on the number of citations they receive; due to their relative availability and accessibility (Knoth \& Herrmannova, 2014). Yet, one should bear in mind that citations represent only one of the attributes of publications. By themselves, they do not provide adequate and sufficient evidence of impact and quality. This may be due to a wide range of characteristics they exhibit; (i) including the semantics of the citation itself (Knoth \& Herrmannova, 2014), (ii) the motives for citing (Nicolaisen, 2007), (iii) the variations in sentiment (Athar, 2014), (iv) the context of the citation 
(He, Pei, Kifer, Mitra \& Giles, 2010), (v) the popularity of topics, the size of research communities (Moed, 2006), (vi) the time delay for citations to show up (Priem \& Hemminger, 2010), (vii) the skewness of their distribution (Seglen, 1992), (viii) the difference in the types of research papers (Seglen, 1997a) and finally, (ix) the ability to game / manipulate citations (Arnold \& Fowler, 2011).

\section{The Journal Impact Factors (IFs)}

The citations and journal impact factors (IFs) are quantitative and objective indicators that assess published science (Seglen, 1997a). Scholarly impact is a measure of frequency in which an “average article" has been cited over a defined time period in a journal (Glänzel \& Moed, 2002). Journal citation reports are published every year by Thomson-Reuters' Institute of Scientific Information (ISI). These reports feature data for the ranking of the Immediacy Index of articles. This index is the average number of times an article is cited in the year it is published. It is calculated by dividing the number of citations to articles published in a given year by the number of articles published in that year. The ISI (IF) that is published in journal citation reports (JCR) is a ratio of received citations (in its numerator) to published articles, notes or reviews in a journal (in the denominator). Hence, the IF represents the mean of a skewed citation distribution of frequency counts per cited journal title. It is calculated by dividing the number of citations in the most recent calendar year (e.g., 2015) by the total number of articles published in the previous 2 years (i.e., 2013-2014). If a journal recorded an IF of 1.0 in 2010; the articles published in 2014 or 2013 have been cited, on average, one time in 2015 (Hodge \& Lacasse, 2011). The IF is therefore biased towards journals revealing a rapid maturing or decline in citation impact (Moed, 2005). The JCR database continuously records scientific citations as represented by article reference lists that are drawn from a large number of scientific journals (Seglen, 1997b).

The journals' IFs are often determined by technicalities that are unrelated to the scientific quality of articles. Academic authors receive different citation counts for their numerous contributions. For instance, they could have published a single paper in a particular research area that is cited very often by other scholars. Notwithstanding, the IFs also depend on the research field. Their citation rates will determine the journals' IFs, and not vice versa (Seglen, 1997a). Journals with high IFs usually cover large areas of basic research with a rapidly expanding but short lived literature; that use many references per article. The number of references per article and their age distribution varies considerably among subfields. Such differences could distort IFs to the extent 
that journals from different subfields cannot be compared with one another. It may appear that a journal IF indicator takes into account such differences in reference practices among subfields, by dividing a journal's impact by the citation 'average' in the subfields covered by the journal (Seglen, 1997a). Review journals tend to have higher citation rates than other journals (Brooks, 1986). This can be taken into account by an advanced normalised impact indicator that disaggregates journal citation impact and subfield averages by type of document (Seglen, 1997a).

In highly dynamic research fields, such as biochemistry and molecular biology, the research papers may become obsolete in a relatively short period of time. A large proportion of citations are captured by the short term index that is used to calculate journal IFs. On the other hand, there are certain topics whose content is durable in literature. For instance, it is often the case that there is a smaller fraction of short term citations on mathematics. This would translate to lower journal IFs as most research fields could be considered as self-contained. For instance, clinical medicine draws heavily on basic science, but not vice versa. The result is that basic medicine is cited three to five times more than clinical medicine, and this is clearly reflected in the journal IFs (Seglen, 1989). Notwithstanding, in young and rapidly evolving research areas, the number of publications making citations is large relative to the amount of citable material. This leads to high citation rates for articles and high journal impact factors (Seglen, 1997a).

Hodge and Lacasse (2011) held that publishers of core scientific journals could evaluate their prospective contributions by using IF indicators. These authors indicated that in the Nordic countries, researchers were being evaluated according to the journal IFs. Moreover, their use was recently reinforced in Italian universities in order to remedy for the purported subjectivity and bias in academic appointments in higher educational insitutions. Hodge and Lacasse (2011) reported that in several other countries the allocation of resources toward tertiary education is often based on IFs. Therefore, the increased awareness of journal IFs, and their potential use for evaluation is encouraging researchers to publish papers in journals with maximum impact. This is happening at the expense of specialist journals that might actually be the most appropriate vehicles for the research in question.

On the other hand, the impact factor has often been subject of ongoing criticisms by researchers for their methodological and procedural imperfections. Whilst a higher impact factor may indicate journals that are considered to be more prestigious, it does not necessarily reflect the quality or impact of an individual article or researcher. This may be attributable to a wide array of journals 
and research contributions (Hodge and Lacasse, 2011). Top influential journals are usually given higher impact factors. Therefore, researchers in a small field may lack access to journals of equally high citation impact. This puts them at a disadvantage when compared with colleagues in larger fields (Seglen, 1997a).

The article citation rates are measured in comparison to citation impact which is specific to a specific field (Garfield, 1972). Such field corrections range from simply dividing a single article's citation rate by the impact factor of its journal (Moed et al., 1987). Seglen (1997a) claimed that this punishes publication in high impact journals to the use of complex, author specific, field indicators based on reference lists. However, field corrections cannot be simply applied to journal impact factors, as many research areas are dominated by one or a few journals. Yet, the case corrections might merely generate relative impact factors of unit value. Even within large fields, the tendency of journals to subspecialise with certain subjects is likely to generate significant differences in journal impact (Seglen, 1997a).

Journal IFs depend on the research field. It is widely assumed that publication in a high IF will enhance the impact of an article. Researchers publish in high impact journals as their academic peers often judge the quality of their papers by their "wrapping" rather than by their content. The journals' academic clout is considered as a valid evaluation criterion. However, journals cannot in any way be taken as representative of the articles they contain. Even if they could, the journal impact factors would still be far from being quality indicators.

Arguably, the citation impact is primarily a measure of scientific utility rather than one of scientific quality. Very often, the authors' selection of references is subjective and is unrelated to quality. Seglen (1997a) hinted that there is no alternative to having an objective evaluation of qualified experts reviewing the scientific quality of publications. Perhaps, the scientific community ought to concentrate its efforts on quality measures rather than on developing ever more sophisticated versions of useless indicators. Ultimately, it is the scientific content of research papers and their significant contribution to knowledge is what really matters to academia.

Seglen (1997a) maintained that $15 \%$ of the most cited articles account for $50 \%$ of all citations. The most cited $50 \%$ of these articles account for $90 \%$ of citations. In other words, the most cited half of articles are cited on average 10 times as often as the least cited half (Seglen, 1997a). This is exactly the opposite of what evaluations are meant to achieve. A few highly cited articles will 
predominantly determine the value of the journals' impact factor. However, the researchers do not always publish their most citable work in journals of the highest impact, nor do their articles necessarily match the impact of the journals they appear in. Some authors may consider other factors including the journals' subject area; their relevance to the author's speciality; the fairness and rapidity of the editorial process; the probability of acceptance, publication lag and publication cost (page charges) among other issues.

In spite of its wide use, the impact factor has often been the subject of numerous criticisms (Brumback, 2009; Favaloro, 2009). The use of the 2-year citation window, the reliance on the mean in computing impact factors, and the limited number of journals indexed by Thomson ISI are some of the main limitations of the impact factor (Hodge \& Lacasse 2011).

\section{The h-index for Individual Scholars and Institutional Impact}

Hirsch (2005) proposed a new measure of scientific achievement. His h-index attempts to calculate the citation impact of academic publications of researchers. It measures the scholars' productivity by taking into account their most cited papers and the number of citations that they have received in other publications. The h-index assesses the significance and impact of the scholars' cumulative research contributions. This index can also be applied to measure the impact and productivity of academic journals, as well as research groups including university departments or countries (Orduña-Malea \& López-Cózar, 2014; Bornmann \& Daniel, 2005). The journals’ hindex value can be calculated with data from Thomson ISI, Elsevier's Scopus or Google Scholar (Labbe, 2010). It mostly used with the latter one.

The h-index consists of a single number that reports on the authors' academic contributions that have at least the equivalent number of citations (Bornmann \& Daniel, 2007). Hirch's h-index is neither entirely dependent on the number of citations nor on the number of publications. It synthesises both measures as one needs to publish many papers with many citations each in order to achieve a high h-index. The higher the index, the greater the number of significant papers published by an author and the higher the significance of the papers. This index was initially designed to overcome the limitations of other measures of quality and productivity of researchers. It has received a lot of attention from the scientific community in the last few years due to some of their good properties including the easiness of its computation, balance between quantity of publications and their impact and so on (Alonso, Cabrerizo, Herrera-Viedma \& Herrera, 2009). As the h-index is an objective indicator it may play an important role when making decisions about 
promotions, funding allocations and awarding academic prizes (Costas \& Bordons, 2007). Vanclay (2007) suggested that the h-index is robust as it is insensitive to a set of lowly cited papers (the difficulty of increasing the h-index grows exponentially as the researcher has to receive new citations to obtain a higher index).

The h-index metric is not limited to a fixed time period. Hence, the citation window can be set at whatever time frame that could be the most appropriate for any given discipline (Hodge \& Lacasse, 2010). h-index values have been calculated using various citation windows, including 1 year (Braun et al., 2006), 2 years (Bador \& Lafouge, 2010), 5 years (Harzing \& van der Wal, 2009), and even longer (Olden, 2007; Vanclay, 2008). Secondly, the h-index is not based on the mean. Therefore, it could attenuate the effect of highly cited articles on computations of journal quality. Indeed, the h-index is unaffected by those few articles that are highly cited. It accurately reflects the unit of analysis (i.e. journals) (Harzing \& van der Wal, 2009).

The h-index values that are derived from Thomson ISI and Google Scholar tend to exhibit modest to strong correlations, although variations do exist from discipline to discipline. For instance, the management journals have reported coefficients of .55 to .66 (Harzing \& van der Wal, 2009). A correlation of .61 was registered in disciplinary computer science journals. 0.78 was recorded for the interdisciplinary computer science journals (Franceschet, 2010). Google Scholar produces high h-index values due to its wide coverage of academic source material (Orduna-Malea et al., 2015; Labbe, 2010; Hodge \& Lacasse, 2010). This index is increasingly being used in citationbased analyses as it is perceived as accurate by many researchers (Moussa \& Touzani, 2010; Lee, Kraus \& Couldwell, 2009; Mingers, 2009). Therefore, Google Scholar's h-index may be a better measure of journal quality than Thomson's ISI impact factor (for the contributors of social sciences (Orduña-Malea \& López-Cózar, 2014). The h-index's strengths lie in its flexible time frame, its computational method that emphasise the quality and quantity of papers, as well as its source coverage. Courtault and Hayek (2008) indicated that when authors increase the number of research papers to journals, they increase their h-index. They went on to suggest that the value of social scientists cannot be fully evaluated with single results. Very often, researchers are awarded for several outstanding contributions, including their complete works. Alternatively, they may be appraised by their peers for initiating a new sub-discipline. Therefore, the h-index is also a useful characterisation that compares the different contributions of scholars. 
However, the h-index could also present some drawbacks that have been pointed out in relevant literature. Hirsch (2005) himself noted that the h-index should not be used to compare scientists from different disciplines. Moreover, Hirsch noted that there exist some technical limitations, such as the difficulty to obtain the complete output of scientists with very common names (this problem decreases as citation databases improve their records and search engines). Moreover, the h-index depends on the duration of each scientist's career because their pool of publications and citations tends to increase over time (Kelly \& Jennions, 2006). So it might not be suitable to compare scientists at different stages of their career. Costas and Bordons (2007) held that highly cited papers are important for the determination of the h-index. They went on to suggest that extremely cited papers may have a similar or equal h-index as researchers with moderate or high cited papers. They admitted that the research performance is a complex multifaceted endeavour that usually cannot be assessed adequately by means of a single indicator. The best papers in terms of quality will be the most cited in academia. Therefore, the h-index may be considered as a compound measure of productivity and quality, as measured by the number of citations received by the published papers (Courtault \& Hayek, 2008). The h-index considers the papers' citations as proxies that assess their quality. It may appear that there is a good correlation between the prestige of a review and its impact factor. Presumably, authors receive many citations because their papers are published in renowned journals. Of course, these authors may have also published high quality papers in less 'impact' journals for many reasons. Authors are often willing to shorten the publication delay or they may simply experience inconsiderate refereeing (Courtault \& Hayek, 2008).

\section{Webometrics for Higher Education Institutions and Research Centres}

Although research impact metrics can be used to evaluate individual academics, there are other measures that could be used to rank and compare academic institutions. There are currently several international ranking schemes for universities, some of which use citations to estimate the institutions' impact (Buela-Casal, Gutiérrez-Martínez, Bermúdez-Sánchez, \& Vadillo-Muñoz, 2007). Nevertheless, there have been ongoing debates about whether bibliometric methods should be used for the ranking of academic institutions (e.g., van Raan 2005; Ioannidis et al., 2007). The science of webometrics (which is also known as cybermetrics) is still in an experimental phase (Thelwall, 2004; Kretschmer \& Aguillo, 2004; Thelwall, 2002; Thelwall \& Price, 2003). Early webometric studies explored how hyperlinks to research papers were used to generate impact indicators. In fact, these studies were structurally similar to citations (Ingwersen, 1998; Smith, 1999). 
Relevant theoretical underpinnings have shown that the number of links to British university web sites were also correlated to their research productivities (Thelwall, 2001). The most productive universities were increasingly enclosing the link to their papers online (Thelwall \& Harries, 2004). Yet, many commentators argued that these hyperlinks were unreliable indicators of journal impact (Kenekayoro, Buckley \& Thelwall, 2014; Smith, 1999; Vaughan \& Hysen, 2002). Yet, several universities were experimenting with different methodological innovations such as mapping to popular web sites through links (Thelwall, Vaughan, and Björneborn, 2005; Vaughan and Shaw, 2005, 2007). Apparently, the scope of webometrics was to link the research organisations with firms, intermediary groups including professional associations and government agencies. Hence, the webometrics were intended to compliment traditional bibliometrics as they kept a track record of publications. Notwithstanding, the web helps to promote research funding initiatives and to advertise academic related jobs. The webometrics could also monitor the extent of mutual awareness in particular research areas (Thelwall, Klitkou, Verbeek, Stuart \& Vincent, 2010).

Aguillo, Granadino, Ortega and Prieto (2006) reported how webometrics were used to rank the academic standing of universities. In this case, the webometrics measured the higher educational institutions' wider impact rather than just their research impact. Moreover, there were other uses of webometric indicators in policy-relevant contexts within the European Union (Thelwall et al., 2010; Hoekman, Frenken \& Tijssen, 2010). The webometrics refer to the quantitative analysis of web activity, including profile views and downloads (Davidson, Newton, Ferguson, Daly, Elliott, Homer, Duffield \& Jackson, 2014). Therefore, webometric ranking involves the measurement of volume, visibility and impact of web pages. These metrics seem to emphasise on scientific output including peer-reviewed papers, conference presentations, preprints, monographs, theses and reports. They also analyse other academic material including courseware, seminar documentation, digital libraries, databases, multimedia, personal pages and blogs among others (Thelwall, 2009; Kousha \& Thelwall, 2015; Mas-Bleda, Thelwall, Kousha \& Aguillo, 2014a; Mas-Bleda, Thelwall, Kousha \& Aguillo, 2014b; Orduna-Malea \& Ontalba-Ruipérez, 2013). Thelwall and Kousha (2013) have identified and explained the methodology of five well-known institutional ranking schemes:

- "QS World University Rankings aims to rank universities based upon academic reputation $(40 \%$, from a global survey), employer reputation (10\%, from a global survey), faculty-student ratio (20\%), citations per faculty (20\%, from Scopus), the proportion of international students $(5 \%)$, and the proportion of international faculty $(5 \%)$. 
- The World University Rankings: aims to judge world class universities across all of their core missions - teaching, research, knowledge transfer and international outlook by using the Web of Science, an international survey of senior academics and self-reported data. The results are based on field-normalised citations for five years of publications (30\%), research reputation from a survey (18\%), teaching reputation (15\%), various indicators of the quality of the learning environment (15\%), field-normalised publications per faculty ( $8 \%$ ), field-normalised income per faculty $(8 \%)$, income from industry per faculty $(2.5 \%)$; and indicators for the proportion of international staff $(2.5 \%)$, students $(2.5 \%)$, and internationally coauthored publications (2.5\%, field-normalised).

- The Academic Ranking of World Universities (ARWU) aims to rank the "world top 500 universities" based upon the number of alumni and staff winning Nobel Prizes and Fields Medals, number of highly cited researchers selected by Thomson Scientific, number of articles published in journals of Nature and Science, number of articles indexed in Science Citation Index - Expanded and Social Sciences Citation Index, and per capita performance with respect to the size of an institution.

- The CWTS Leiden Ranking aims to measure "the scientific performance" of universities using bibliometric indicators based upon Web of Science data through a series of separate size- and field-normalised indicators for different aspects of performance rather than a combined overall ranking. For example, one is "the proportion of the publications of a university that, compared with other publications in the same field and in the same year, belong to the top $10 \%$ most frequently cited" and another is "the average number of citations of the publications of a university, normalised for field differences and publication year."

- The Webometrics Ranking of World Universities Webometrics Ranking aims to show "the commitment of the institutions to [open access publishing] through carefully selected web indicators": hyperlinks from the rest of the web (1/2), web site size according to Google (1/6), and the number of files in the website in "rich file formats" according to Google Scholar (1/6), but also the field-normalised 
number of articles in the most highly cited $10 \%$ of Scopus publications (1/6)" (Thelwall \& Kousha, 2013).

Evidently, the university ranking systems use a variety of factors in their calculations, including their web presence, the number of publications, the citations to publications and peer judgements (Thelwall and Kousha, 2013; Aguillo, Bar-Ilan, Levene, \& Ortega, 2010). These metrics typically reflect a combination of different factors, as shown above. Although they may have different objectives, they tend to give similar rankings. It may appear that the universities that produce good research also tend to have an extensive web presence, perform well on teaching-related indicators, and attract many citations.

On the other hand, the webometrics may not necessarily provide robust indicators of knowledge flows or research impact. In contrast to citation analysis, the quality of webometric indicators is not high unless irrelevant content is filtered out, manually. Moreover, it may prove hard to interpret certain webometric indicators as they could reflect a range of phenomena ranging from spam to post publication material. Webometric analyses can support science policy decisions on individual fields. However, for the time being, it is difficult to tackle the issue of web heterogeneity in lower field levels (Thelwall \& Harries, 2004; Wilkinson, Harries, Thelwall \& Price, 2003). Moreover, Thelwall et al., (2010) held that webometrics would not have the same relevance for every field of study. It is very likely that fast moving or new research fields could not be adequately covered by webometric indicators due to publication time lags. Thelwall et al. (2010) argued that it could take up to two years to start a research and to have it published. This would therefore increase the relative value of webometrics as research groups can publish general information online about their research.

\section{Online Academic Networks}

Webometric measures ought to be combined with other approaches, whenever possible (Thelwall et al., 2010). Prolific authors publish both in high impact as well as in lower impact journals. They also use online academic networks to engage with other scholars who share their same research interests. Web 2.0 applications can be turned into productive social research tools (Thelwall \& Kousha, 2015a, 2015b; Henning \& Reichelt, 2008). Multi-purpose social software, such as wikis, blogs, and social networks are increasingly being utilised and evaluated by a number of researchers and academics. At the same time, many individuals are developing and publishing their user generated content, online. In a similar, it has never been so easy for academics to 
engage with their peers. Many scholars are creating their own personal web sites and blogs to enhance the visibility of their publications. This medium has improved the academic marketing in addition to the traditional bibliometrics (Camilleri, 2015). Besides, the influence of social media has also changed the academic publishing scenario. For instance, scholars share ideas, common interests, as well as promoting their scientific findings on social media (Davidson et al., 2014). Evidently, there has been a rapid proliferation in the uptake of Twitter as it is used for networking purposes (Thelwall et al., 2013). Moreover, other academic social networking sites including Academia.edu and ResearchGate as well as reference sharing sites including Mendeley, Bibsonomy, Zotero and CiteULike scholars are also publicising academic contributions.

During these last few years, several academics have created their own profiles on social academic networks. They list their publications and interact with each other. These online networks provide a new way for scholars to disseminate their work as they change the dynamics of informal scholarly communication. Interestingly, Thelwall and Kousha (2014) found that the rankings based on ResearchGate's statistics were moderately correlating with other rankings of academic institutions. These results indicated that the RG score from ResearchGate had correlated well with other university rankings (Thelwall and Kousha, 2015c). Yet, this may not be the case with other social networks. However, the social media sites are free to use, and they may provide a more democratic way for universities to reach out to the various audiences and interest groups.

Forkosh-Baruch and Hershkovitz's (2012) indicated that "the potential of SNS [social networking sites] as means of sharing academic knowledge in higher education institutes had not been actualised at the time of their study. Nevertheless, Vaughan and Romero-Frías (2014) noticed that the highly ranked universities have attracted more attention in Google Trends. These authors indicated that a great amount of searches for the US universities came from outside the US, whilst only a few searches for the Spanish universities came from outside of Spain. These findings may have also reflected the international positions of the two sets of universities. Thelwall and Kousha (2015c) took another approach to study universities' online presences as they investigated whether the usage of ResearchGate and its publications were somehow related to the "academic hierarchies" of different university rankings. Thelwall and Kousha (2015c) held that the RG score "broadly reflected the traditional academic capital".

It may appear that the universities' usage of social media and the attention they receive there is still relatively unclear. Academic visibility in social media is measured by various metrics 
(Bollen, Van De Sompel, Hagberg \& Chute, 2009; Lin \& Fenner, 2013). These new social media metrics, the so called altmetrics, could potentially give a more nuanced view of the attention towards research outputs (Priem, Piwowar \& Hemminger, 2012). The underlying premise is that, for example, mentions in blogs, number of re-tweets or saves of articles in reference management systems, may be a valid measure of the use of scientific publications (Holmberg, 2015). As a matter of fact, recently there has been an increased recognition for additional measures of scholarly contributions that are published online (Delgado López-Cózar et al., 2014). For instance, Bornmann (2014) suggested that altmetrics could provide indicators for the societal impact of research or provide some insight on the research interests of other audiences outside academia (Haustein, Peters, Bar-Ilan, Priem, Shema \& Terliesner, 2014). On the other hand, Thelwall, Haustein, Larivière and Sugimoto (2013) identified some of the weaknesses of altmetrics. They noted that the older articles were not experiencing high altmetric scores as opposed to the latest articles. In the past, there academic journals did not have social media plugins. They argued that very often scholars were searching for the most recent articles in academic literature.

\section{CONCLUSIONS AND FINAL REMARKS}

The content marketing of academic material involves a series of metrics that measure the researchers' or their institutions' 'impact', 'influence' or 'quality' of their contributions. There are various sources of bibliometric data, and each possess their own strengths and limitations. For example, the emerging field of altmetrics is concerned with impact measures rather than scholarly communication itself (Thelwall et al., 2013; Lin \& Fenner, 2013; Priem et al., 2012). For the time being, there is no single bibliometric measure that is perfect. Multiple approaches to evaluation are highly recommended. Moreover, bibliometric and webometric approaches should not be the only measures upon which academic and scholarly performance ought to be evaluated. Sometimes, the use of bibliometric indicators could reduce the publications' impact to a quantitative, numerical scores. Many commentators have argued that when viewed in isolation these metrics may not necessarily be representative of a researcher's performance or capacity. Nonetheless, bibliometrics still have their high utility in academia. It is very likely that the metrics that were mentioned in this contribution will still to continue to be in use, in the foreseeable future. They represent a relatively simple and accurate data source. Undoubtedly, bibliometrics are an essential aspect for the measurement of academic clout and organisational performance. This chapter has identified a number of systematic ways of assessment; including citation analysis, impact factor, webometrics and social academic networks among others. The researchers' and their academic institutions' outputs are continuously being evaluated as 
independent reviewers frequently measure the quality and quantity of their academic publications. It transpires that citations are conspicuous in highly reputable journals or well-linked web sites that contain relevant scholarly content. This contribution has indicated that the most cited authors are recognised by their peers for their significant findings. In a similar vein, the highly reputable journals that have high impact factors are renowned for their contribution to knowledge, as their publications are sought by numerous researchers and scholars for their academic standing.

This chapter suggests that recognition by peers can help to boost the researchers' and their educational institutions' productivity levels. It has mentioned many issues that revolve on the research evaluation of academic content. A thorough literature review on scholarly impact and academic reputation indicated that the most cited contributions, journals and educational institutions are utilising a wide array of metrics to raise their standing. Researchers have become increasingly aware of the potential of personal branding. Nevertheless, their scholarly impact depends on a number of factors including the accessibility of publications, the peer review of their academic work as well as ongoing social networking and fruitful collaborative relationships with other scholars. Notwithstanding, the ongoing changes in academic behaviours and their use of content marketing on internet seem to have challenged the traditional metrics. Evidently, there is more to the measurement of impact than citation metrics. In this digital era, researchers are getting acquainted with WEB2.0. The ubiquity of online academic networks is also helping individual scholars' to establish performance and impact. At the same time, they are continuously sharing resources as they engage with colleagues. Social networks such as ResearchGate, Academia.edu, among others; have become new outlets for the publication of academic research.

In conclusion, this chapter has critically reviewed the extant literature on bibliometrics, webometrics, altimetrics and mentioned a few social networks for academic marketing. It clearly explained how content marketing of individual researchers' and educational institutions' contributions may lead to better academic standing and increased reputation.

\section{Future Research Avenues}

This chapter has presented relevant theoretical underpinnings on metrics that measure academic clout. It has also shed light on particular social networks that are increasingly disseminating research, online. The author believes that further research ought to re-examine the communication structures and processes of academic communications among researchers and their institutions. 
For instance, at the moment we are witnessing an evolution of webometrics. Researchers are increasingly using the web to enhance the visibility of their publications. Future empirical studies could reassess the importance of the web as a communication medium. Nowadays, social academic networks are already hosting a myriad of academic resources; ranging from journal articles, chapters, books, teaching resources, presentations and the like. Given the proliferation of accessible sources of research, there are limitless possibilities for scientists to raise their academic profile among their peers. Therefore, additional research could possibly shed light on the latest techniques and issues that are being used to promote scholarly research across different fields and subfields. Notwithstanding, this research area is relatively wide as it includes educational institutions, research entities such as intermediary groups like professional and trade associations as well as government agencies.

\section{REFERENCES}

Adler, N. J., \& Harzing, A. W. (2009). When knowledge wins: Transcending the sense and nonsense of academic rankings. Academy of Management Learning \& Education, 8(1), 72-95.

Aguillo, I. F., Granadino, B., Ortega, J. L., \& Prieto, J. A. (2006). Scientific research activity and communication measured with cybermetrics indicators. Journal of the American Society for information science and technology, 57(10), 1296-1302.

Alonso, S., Cabrerizo, F. J., Herrera-Viedma, E., \& Herrera, F. (2009). h-Index: A review focused in its variants, computation and standardization for different scientific fields. Journal of Informetrics, 3(4), 273-289

Arnold, D. N., \& Fowler, K. K. (2011). Nefarious numbers. Notices of the AMS, 58(3), 434-437.

Athar, A. (2014). Sentiment analysis of scientific citations. University of Cambridge, Computer Laboratory, Technical Report, (UCAM-CL-TR-856).

Bar-Ilan, J. (2004). A microscopic link analysis of academic institutions within a country-the case of Israel. Scientometrics, 59(3), 391-403. 
Bador, P., \& Lafouge, T. (2010). Analyse comparative du facteur d'impact et du h-index pour les journaux de pharmacologie. Thérapie, 65(2), 129-137.

Björneborn, L., \& Ingwersen, P. (2004). Toward a basic framework for webometrics. Journal of the American Society for Information Science and Technology, 55(14), 1216-1227.

Bollen, J., Van de Sompel, H., Hagberg, A., \& Chute, R. (2009). A principal component analysis of 39 scientific impact measures. PloS one, 4(6), e6022.

Bonzi, S., \& Snyder, H. W. (1991). Motivations for citation: A comparison of self citation and citation to others. Scientometrics, 21(2), 245-254.

Borgman, C. L. (2000). Digital libraries and the continuum of scholarly communication. Journal of documentation, 56(4), 412-430.

Borgman, C. L., \& Furner, J. (2002). Scholarly communication and bibliometrics, 36, 3-72.

Bornmann, L., \& Daniel, H. D. (2005). Does the h-index for ranking of scientists really work?. Scientometrics, 65(3), 391-392.

Bornmann, L., \& Daniel, H. D. (2007). What do we know about the h index?. Journal of the American Society for Information Science and technology, 58(9), 1381-1385.

Bornmann, L. (2014). Do altmetrics point to the broader impact of research? An overview of benefits and disadvantages of altmetrics. Journal of informetrics, 8(4), 895-903.

Braun, T., Glänzel, W., \& Schubert, A. (2006). A Hirsch-type index for journals. Scientometrics, 69(1), 169-173.

Brooks, T. A. (1986). Evidence of complex citer motivations. Journal of the American Society for Information Science, 37(1), 34-36.

Brumback, R. A. (2009). Impact factor wars: episode V-the empire strikes back. Journal of child neurology, 24(3), 260. 
Camilleri, M.A. (2015a). Using Big Data for Customer-Centric Marketing. In Handbook of Research on Open Data Innovations in Business and Government, IGI Global. Retrieved April 15, 2015, from http://www.researchgate.net/publication/275349565_Using_Big_Data_for_CustomerCentric_Marketing

Costas, R., \& Bordons, M. (2007). The h-index: Advantages, limitations and its relation with other bibliometric indicators at the micro level. Journal of Informetrics, 1(3), 193-203.

Courtault, J. M., \& Hayek, N. (2008). On the Robustness of the h-index: a mathematical approach. Economics Bulletin, 3(78), 1-9.

Courtault, J. M., Hayek, N., Rimbaux, E., \& Zhu, T. (2010). Research in economics and management in France: A bibliometric study using the h-index. The Journal of Socio-Economics, 39(2), 329-337.

Davidson, P. M., Newton, P. J., Ferguson, C., Daly, J., Elliott, D., Homer, C., ... \& Jackson, D. (2014). Rating and Ranking the Role of Bibliometrics and Webometrics in Nursing and Midwifery. The Scientific World Journal, 2014.

Delgado López-Cózar, E., Robinson-García, N., \& Torres-Salinas, D. (2014). The Google Scholar Experiment: how to index false papers and manipulate bibliometric indicators. Journal of the Association for Information Science and Technology, 65(3), 446-454.

Eysenbach, G. (2011). Can tweets predict citations? Metrics of social impact based on Twitter and correlation with traditional metrics of scientific impact. Journal of medical Internet research, $13(4)$.

Favaloro, E. J. (2009). The journal impact factor: Don't expect its demise any time soon. Clinical Chemistry and Laboratory Medicine, 47(11), 1319-1324.

Franceschet, M. (2010). Ten good reasons to use the Eigenfactor ${ }^{\mathrm{TM}}$ metrics. Information Processing \& Management, 46(5), 555-558. 
Garfield, E. (1972). Citation analysis as a tool in journal evaluation. American Association for the Advancement of Science. Retrieved April 15, 2015, from http://www.elshami.com/Terms/I/impact\%20factor-Garfield.pdf

Garfield, E. (1979). Is citation analysis a legitimate evaluation tool?. Scientometrics, 1(4), 359375.

Glänzel, W., \& Moed, H. F. (2002). Journal impact measures in bibliometric research. Scientometrics, 53(2), 171-193.

Glänzel, W. (2006). On the h-index-A mathematical approach to a new measure of publication activity and citation impact. Scientometrics, 67(2), 315-321.

Harzing, A. W., \& Van Der Wal, R. (2009). A Google Scholar h-index for journals: An alternative metric to measure journal impact in economics and business. Journal of the American Society for Information Science and Technology, 60(1), 41-46.

Haustein, S., Peters, I., Bar-Ilan, J., Priem, J., Shema, H., \& Terliesner, J. (2014). Coverage and adoption of altmetrics sources in the bibliometric community. Scientometrics, 101(2), 1145-1163.

He, Q., Pei, J., Kifer, D., Mitra, P., \& Giles, L. (2010). Context-aware citation recommendation. In Proceedings of the 19th international conference on World wide web (pp. 421-430). ACM.

Henning, V., \& Reichelt, J. (2008, December). Mendeley-a last. fm for research?. In eScience, 2008. eScience'08. IEEE Fourth International Conference on (pp. 327-328). Retrieved January 22, 2015, from http://blog.mendeley.com/wp-content/uploads/2009/05/henning-reichelt-2008mendeley-a-lastfm-for-research-ieee-e-science.pdf

Hirsch, J. E. (2005). An index to quantify an individual's scientific research output. Proceedings of the National academy of Sciences of the United States of America, 102(46), 16569-16572.

Hoekman, J., Frenken, K., \& Tijssen, R. J. (2010). Research collaboration at a distance: Changing spatial patterns of scientific collaboration within Europe. Research Policy, 39(5), 662-673. 
Hodge, D. R., \& Lacasse, J. R. (2010). Evaluating journal quality: Is the H-index a better measure than impact factors?. Research on Social Work Practice.

Holmberg, K. J. (2015). Altmetrics for Information Professionals: Past, Present and Future. Chandos Publishing.

Ingwersen, P. (1998). The calculation of web impact factors. Journal of documentation, 54(2), 236-243.

Kelly, C. D., \& Jennions, M. D. (2006). The h index and career assessment by numbers. Trends in Ecology \& Evolution, 21(4), 167-170.

Kenekayoro, P., Buckley, K., \& Thelwall, M. (2014). Hyperlinks as inter-university collaboration indicators. Journal of Information Science, 40(4), 514-522.

Knoth, P., \& Herrmannova, D. (2014). Towards Semantometrics: A New Semantic Similarity Based Measure for Assessing a Research Publication's Contribution. D-Lib Magazine, 20(11), 8.

Knothe, G. (2006). Comparative citation analysis of duplicate or highly related publications. Journal of the American Society for Information Science and Technology, 57(13), 1830-1839.

Kousha, K., \& Thelwall, M. (2007). Google Scholar citations and Google Web/URL citations: A multi-discipline exploratory analysis. Journal of the American Society for Information Science and Technology, 58(7), 1055-1065.

Kousha, K., \& Thelwall, M. (2015). Web indicators for research evaluation. Part 3: books and non standard outputs. El profesional de la información,24(6), 724-736.

Kretschmer, H., \& Aguillo, I. (2004). Visibility of collaboration on the Web.Scientometrics, 61(3), 405-426.

Labbé, C. (2010). Ike Antkare one of the great stars in the scientific firmament. ISSI newsletter, $6(2), 48-52$. 
Lee, J., Kraus, K. L., \& Couldwell, W. T. (2009). Use of the h index in neurosurgery: clinical article. Journal of neurosurgery, 111(2), 387-392.

Lin, J., \& Fenner, M. (2013). Altmetrics in evolution: defining and redefining the ontology of article-level metrics. Information Standards Quarterly, 25(2), 20.

Mas-Bleda, A., Thelwall, M., Kousha, K., \& Aguillo, I. F. (2014). Do highly cited researchers successfully use the social web?. Scientometrics, 101(1), 337-356.

Mas-Bleda, A., Thelwall, M., Kousha, K., \& F. Aguillo, I. (2014). Successful researchers publicizing research online: An outlink analysis of European highly cited scientists' personal websites. Journal of Documentation, 70(1), 148-172.

Mingers, J. (2009). Measuring the research contribution of management academics using the Hirsch-index. Journal of the Operational Research Society, 60(9), 1143-1153.

Moed, H. F., Burger, W. J. M., Frankfort, J. G., \& Van Raan, A. F. (1985). The use of bibliometric data for the measurement of university research performance. Research Policy, 14(3), 131-149.

Moed, H. F. (2005). Statistical relationships between downloads and citations at the level of individual documents within a single journal. Journal of the American Society for Information Science and Technology, 56(10), 1088-1097.

Moed, H. F. (2006). Citation analysis in research evaluation (Vol. 9). Springer Science \& Business Media.

Moussa, S., \& Touzani, M. (2010). Ranking marketing journals using the Google Scholar-based hg-index. Journal of Informetrics, 4(1), 107-117.

Nicolaisen, J. (2007). Citation analysis. Annual review of information science and technology, $41(1), 609-641$. 
Olden, J. D. (2007). How do ecological journals stack-up? Ranking of scientific quality according to the h index. Ecoscience, 14(3), 370-376.

Orduna-Malea, E., \& Ontalba-Ruipérez, J. A. (2013). Selective linking from social platforms to university websites: a case study of the Spanish academic system. Scientometrics, 95(2), 593-614.

Orduña-Malea, E., \& López-Cózar, E. D. (2014). Google Scholar Metrics evolution: an analysis according to languages. Scientometrics,98(3), 2353-2367

Orduna-Malea, E., Ayllón, J. M., Martín-Martín, A., \& López-Cózar, E. D. (2015). Methods for estimating the size of Google Scholar. Scientometrics, 104(3), 931-949.

Priem, J., \& Hemminger, B. H. (2010). Scientometrics 2.0: New metrics of scholarly impact on the social Web. First Monday, 15(7).

Priem, J., Piwowar, H. A., \& Hemminger, B. M. (2012). Altmetrics in the wild: Using social media to explore scholarly impact. Cornell University Working Paper. Retrieved May 2, 2016 from http://arxiv.org/abs/1203.4745

Rimbaux, E. (2010) Research in Economics and Management in France. Retrieved April 10, 2015, from http://core.ac.uk/download/pdf/6508361.pdf

SciVerse Scopus (2015). About Scopus. Retrieved April 15, 2015, from http://www.elsevier.com/solutions/scopus

Seglen, P. O. (1989). From bad to worse: evaluation by Journal Impact. Trends in biochemical Sciences, 14(8), 326-327.

Seglen, P. O. (1992). The skewness of science. Journal of the American Society for Information Science, 43(9), 628-638.

Seglen, P. O. (1997a). Why the impact factor of journals should not be used for evaluating research. Bmj, 314(7079), 497. 
Seglen, P. O. (1997b). Citations and journal impact factors: questionable indicators of research quality. Allergy, 52(11), 1050-1056.

Shuai, X., Pepe, A., \& Bollen, J. (2012). How the scientific community reacts to newly submitted preprints: Article downloads, twitter mentions, and citations.

Smith, A. G. (1999). A tale of two web spaces: comparing sites using web impact factors. Journal of documentation, 55(5), 577-592.

Tague-Sutcliffe, J. (1992). An introduction to informetrics. Information processing \& management, 28(1), 1-3.

Thelwall, M. (2001). Results from a web impact factor crawler. Journal of Documentation, 57(2), 177-191.

Thelwall, M. (2002). Conceptualizing documentation on the Web: An evaluation of different heuristic-based models for counting links between university Web sites. Journal of the American Society for Information Science and Technology, 53(12), 995-1005.

Thelwall, M., \& Price, L. (2003). Disciplinary differences in academic web presence-a statistical study of the UK. Libri, 53(4), 242-253.

Thelwall, M., \& Tang, R. (2003). Disciplinary and linguistic considerations for academic Web linking: An exploratory hyperlink mediated study with Mainland China and Taiwan. Scientometrics, 58(1), 155-181.

Thelwall, M. (2004). Link analysis: An information science approach. Academic Press, Elsevier UK.

Thelwall, M., \& Harries, G. (2004). Can personal web pages that link to universities yield information about the wider dissemination of research?. Journal of Information Science, 30(3), $240-253$ 
Thelwall, M., Vaughan, L., \& Björneborn, L. (2005). Webometrics. Annual review of information science and technology, 39(1), 81-135.

Thelwall, M. (2008). Bibliometrics to webometrics. Journal of information science. Retrieved April 24, 2016 from http://jis.sagepub.com/content/early/2008/06/13/0165551507087238.short

Thelwall, M. (2009). Introduction to webometrics: Quantitative web research for the social sciences.

Morgan \& Claypool.

Thelwall, M., Klitkou, A., Verbeek, A., Stuart, D., \& Vincent, C. (2010). Policy-relevant Webometrics for individual scientific fields. Journal of the American Society for Information Science and Technology, 61(7), 1464-1475.

Thelwall, M., Haustein, S., Larivière, V., \& Sugimoto, C. R. (2013). Do altmetrics work? Twitter and ten other social web services.

Thelwall, M., \& Kousha, K. (2015a). Web indicators for research evaluation. Part 1: Citations and links to academic articles from the Web. El profesional de la información, 24(5), 587-606.

Thelwall, M., \& Kousha, K. (2015b). Web indicators for research evaluation. Part 2: Social media metrics. El profesional de la información, 24(5), 607-620.

Thelwall, M., \& Kousha, K. (2015c). ResearchGate: Disseminating, communicating, and measuring Scholarship?. Journal of the Association for Information Science and Technology, 66(5), 876-889.

Thomson Reuters ISI Web of Science (2010). Web of Science Retrieved April 17, 2015, from http://thomsonreuters.com/en/products-services/scholarly-scientific-research/scholarly-searchand-discovery/web-of-science.html

Vanclay, J. K. (2008). Ranking forestry journals using the h-index. Journal of informetrics, 2(4), 326-334. 
Vaughan, L., \& Romero-Frías, E. (2014). Web search volume as a predictor of academic fame: An exploration of Google trends. Journal of the Association for Information Science and Technology, 65(4), 707-720.

Vaughan, L., \& Shaw, D. (2005). Web citation data for impact assessment: A comparison of four science disciplines. Journal of the American Society for Information Science and Technology, 56(10), 1075-1087.

Vaughan, L., \& Shaw, D. (2007). A new look at evidence of scholarly citation in citation indexes and from web sources. Scientometrics, 74(2), 317-330.

Wilkinson, D., Harries, G., Thelwall, M., \& Price, L. (2003). Motivations for academic Web site interlinking: Evidence for the Web as a novel source of information on informal scholarly communication. Journal of information science, 29(1), 49-56.

Wilson, C. S. (1999). Informetrics. Annual Review of Information Science and Technology (ARIST), 34, 107-247. 